\title{
Análise da mortalidade por causas externas, Santa Catarina, 2008 a 2017
}

\author{
Analysis of mortality from external causes, Santa Catarina, 2008 to 2017 \\ Análisis de mortalidad por causas externas, Santa Catarina, 2008 a 2017 \\ João Augusto Brancher Fuck ${ }^{1 *}$, Gláucia de Oliveira Assis ${ }^{1}$, Carmen Susana Tornquist ${ }^{1}$.
}

\section{RESUMO}

Objetivo: Analisar os óbitos por causas externas em Santa Catarina, no período de 2008 a 2017. Métodos: Estudo epidemiológico descritivo com dados secundários do Sistema de Informações sobre Mortalidade. Resultados: As causas externas se apresentam como uma das principais causas de óbito em Santa Catarina. Os óbitos não estão distribuídos de forma uniforme no território catarinense, com concentração $(49,8 \%)$ em quatro regiões de saúde. Entre as principais causas estão os acidentes de transporte - ocupantes de motos, veículos e pedestres, as quedas e afogamentos, as agressões por armas de fogo e as lesões autoprovocadas por enforcamento. No período analisado, observou-se uma queda da taxa de mortalidade por acidentes de transporte e, ao mesmo tempo, aumento por agressões. Os homens na faixa etária entre 20 a 49 anos são os mais afetados. As mortes em pessoas brancas representam $87,3 \%$ do total, embora as pessoas pretas e pardas morrem em proporções maiores na faixa etária entre 20 e 49 anos, assim como é maior o número de mortes por agressões. Conclusão: A mortalidade por causas externas e, portanto, evitáveis, constitui um importante problema de saúde pública e afeta de forma diferente as pessoas segundo o sexo, cor e faixa etária.

Palavras-chave: Causas externas, Violência, Mortalidade, Epidemiologia.

\begin{abstract}
Objective: Analyze deaths from external causes in Santa Catarina, from 2008 to 2017. Methods: Descriptive epidemiological study based on secondary data from the Mortality Information System. Results: External causes may present as one of the main causes of death in Santa Catarina. Deaths are not evenly distributed in the territory of Santa Catarina, with a concentration $(49,8 \%)$ in four health regions. Among the main causes are transport accidents - involving motorcycle, vehicle and pedestrian occupants, falls and drowning, assaults by firearms and self-harm by hanging. During the period analyzed, there may be a mortality rate due to traffic accidents and, at the same time, increased aggression. Men aged 20 to 49 are the most affected. Deaths in white people represent $87.3 \%$ of the total, although black and brown people die in greater proportions in the age group between 20 and 49 years, just as the number of deaths due to aggression is higher. Conclusion: Mortality from external causes, and therefore preventable, presents an important public health problem and affect people differently according to sex, color and age group.
\end{abstract}

Key words: External causes, Violence, Mortality, Epidemiology.

\section{RESUMEN}

Objetivo: Analizar las muertes por causas externas en Santa Catarina, de 2008 a 2017. Métodos: Estudio epidemiológico descriptivo con datos secundarios del Sistema de Información de Mortalidad. Resultados: Las causas externas son una de las principales causas de muertes en Santa Catarina. Las muertes no se distribuyen uniformemente en Santa Catarina, con una concentración $(49,8 \%)$ en cuatro regiones de salud. Entre las causas principales se encuentran los accidentes de transporte - ocupantes de motocicletas, vehículos e peatones, caídas y ahogamientos, asaltos con armas de fuego y autolesiones al ahorcarse. En el período analizado, hubo una disminución en la tasa de mortalidad debido a accidentes de transporte y, al mismo tiempo, un aumento debido a las agresiones. Los hombres de 20 a 49 años son los más afectados.

${ }^{1}$ Programa de Pós-Graduação em Planejamento Territorial e Desenvolvimento Socioambiental (PPGPLAN). Universidade do Estado de Santa Catarina (UDESC), Florianópolis - SC. *E-mail: joaooabf@gmail.com 
Las muertes en personas blancas representan el $87.3 \%$ del total, aunque las personas negras y marrones mueren en mayores proporciones en el grupo de edad entre 20 y 49 años, al igual que el número de muertes debido a la agresión es mayor. Conclusión: La mortalidad por causas externas, y por lo tanto prevenible, es un importante problema de salud pública y afecta a las personas de manera diferente según el sexo, el color y el grupo de edad.

Palabras clave: Causas externas, Violencia, Mortalidad, Epidemiología.

\section{INTRODUÇÃO}

Nas últimas décadas, a violência vem aumentando de forma significativa no Brasil, processo que encontra expressão em elevados indicadores epidemiológicos e criminais oficiais. Desde a década de 1980 os principais centros urbanos do país vêm apresentando um aumento nas mortes por causas externas, com elevadas taxas de homicídios e acidentes de trânsito, envolvendo principalmente a população jovem, masculina e negra (SOUZA ER e LIMA ML, 2006). A magnitude deste crescimento é surpreendente e o Brasil fica em quarto lugar no ranking das mortes violentas do mundo, na análise das informações dos primeiros anos do século XXI (WAISELFISZ JJ, 2007). Embora Santa Catarina (SC) apresente umas das menores taxas do Brasil, chama atenção o crescimento de 47,7\% nos óbitos por homicídios entre 2006 e 2016 (CERQUEIRA D, et al., 2018).

Para fins deste artigo, consideramos violência como sendo as ações de indivíduos, grupos, classes ou nações, ocasionando a morte de outros seres humanos ou prejudicando sua integridade física, moral, mental e espiritual. Assim, é um tema complexo de ser abordado nos esquemas convencionais das disciplinas de saúde coletiva, tendo em vista a carga de ideologia, preconceito e senso comum que acompanham sua discussão (MINAYO MCS e SOUZA ER, 1998). Por ser determinada por uma pluricausalidade, não pode ser compreendida simplesmente como fator individual ou biológico, mas sim como um processo social. Assim, assinalamos que estamos diante de um fenômeno de grande complexidade e de caráter multideterminado (MINAYO MCS e SOUZA ER, 1998; MINAYO MCS e SOUZA ER, 1999; SOUZA ER e LIMA MLC, 2006). Nesta via, a contribuição da epidemiologia, ainda que limitada, auxilia na análise desse fenômeno nas sociedades contemporâneas.

$\mathrm{Na}$ análise desses óbitos, duas categorias devem ser levadas em consideração: as causas externas e a violência. No primeiro caso, o termo é utilizado pela área da saúde e envolve os homicídios, os suicídios, as agressões físicas, os acidentes de transporte, entre outros de menor incidência, com o objetivo de elaborar perfis de mortalidade, para conhecimento da realidade e elaboração de proposições de intervenção por parte dos órgãos públicos (MINAYO MCS, 2009). De uma forma sintética e operacional, o termo violência, engloba a dimensão social construída a partir das inter-relações, visando prejudicar o outro de alguma forma (MICHAUD Y, 1989). Assim, existe uma distribuição desigual da violência, que afeta diferentemente a população, variando conforme o sexo, cor da pele, idade e inserção no espaço social (SOUZA ER e LIMA MLC, 2006).

Dessa forma, o objetivo deste artigo é realizar uma análise da mortalidade ocasionada pelas causas externas em SC, no período de 2008 a 2017, levando em consideração fatores como faixa etária, sexo e raça. Todavia, consideramos que, para uma análise mais completa dos determinantes sociais da violência - tal como definida aqui - estas bases carecem de outras informações relevantes. Ainda assim, consideramos estes fatores como variáveis importantes que buscamos contemplar na análise.

\section{MÉTODOS}

Estudo epidemiológico descritivo, com o objetivo de analisar os óbitos decorrentes de causas externas em SC. O objetivo de estudos descritivos é compreender a distribuição de um agravo ou doença, com base em informações referentes ao tempo, lugar e características dos indivíduos envolvidos. Essa informação pode ser obtida através dos bancos de dados de abrangência nacional utilizados no Brasil (COSTA MFL e BARRETO SM, 2003). 
Assim, este estudo utilizou dados do Sistema de Informação sobre Mortalidade (SIM), disponibilizados pelo Departamento de Informática do Sistema Único de Saúde, por meio do TabNET. O SIM é o sistema mais antigo do Ministério da Saúde, implantado no país entre os anos de 1975/76. As informações sobre mortalidade são um importante subsídio para o conhecimento do perfil de saúde da população, embora ainda existam limitações quanto ao correto registro da causa básica do óbito (JORGE MHP, et al., 2002; PINTO LF, et al., 2018), bem como outras informações relevantes no que se refere às características dos sujeitos envolvidos.

Os dados utilizados se referem aos óbitos ocorridos entre 2008 e 2017, incluídos nas categorias do capítulo XX da Classificação Internacional de Doenças (CID-10) (ORGANIZAÇÃO MUNDIAL DA SAÚDE, 2012). O recorte espacial selecionado foi o estado de SC, ou seja, o local de residência das vítimas. As variáveis utilizadas no estudo foram: grupos e categorias da CID10, região de saúde de residência, faixa etária, sexo, raça e escolaridade. Para o cálculo das taxas de mortalidade foi utilizado o dado referente a população residente do censo de 2010 e das estimativas populacionais do Instituto Brasileiro de Geografia e Estatística (IBGE) para os demais anos. Quando a taxa de mortalidade foi calculada para o período, utilizou-se a estimativa populacional referente ao ano de 2012. A referência para o cálculo foi de 100 mil habitantes. Os dados foram apresentados em números absolutos, assim como porcentagens e taxas, sendo utilizado o programa Microsoft Office Excel® para tabulação e métrica.

\section{RESULTADOS}

No período de 2008 a 2017 foram registrados, no Brasil, 1.491 .023 óbitos por causas externas, sendo que destes $211.278(14,2 \%)$ ocorreram na Região Sul e $42.523(2,8 \%)$ no estado de SC. As causas externas aparecem como a terceira causa dos óbitos em SC $(11,7 \%)$ ficando atrás apenas das doenças do aparelho circulatório $(28,5 \%)$ e das neoplasias $(20,7 \%)$. No ano de 2008 , foram registrados 4.132 óbitos por causas externas, enquanto em 2017 o número chegou a 4.621. Ocorreram variações referente ao número de mortes nos anos de 2009 e 2013, seguido de um crescimento nos últimos três anos (Gráfico 1).

Gráfico 1 - Número de óbitos e taxa de mortalidade (por 100 mil hab.) por causas externas (CID10). Santa Catarina, 2008 a 2017.

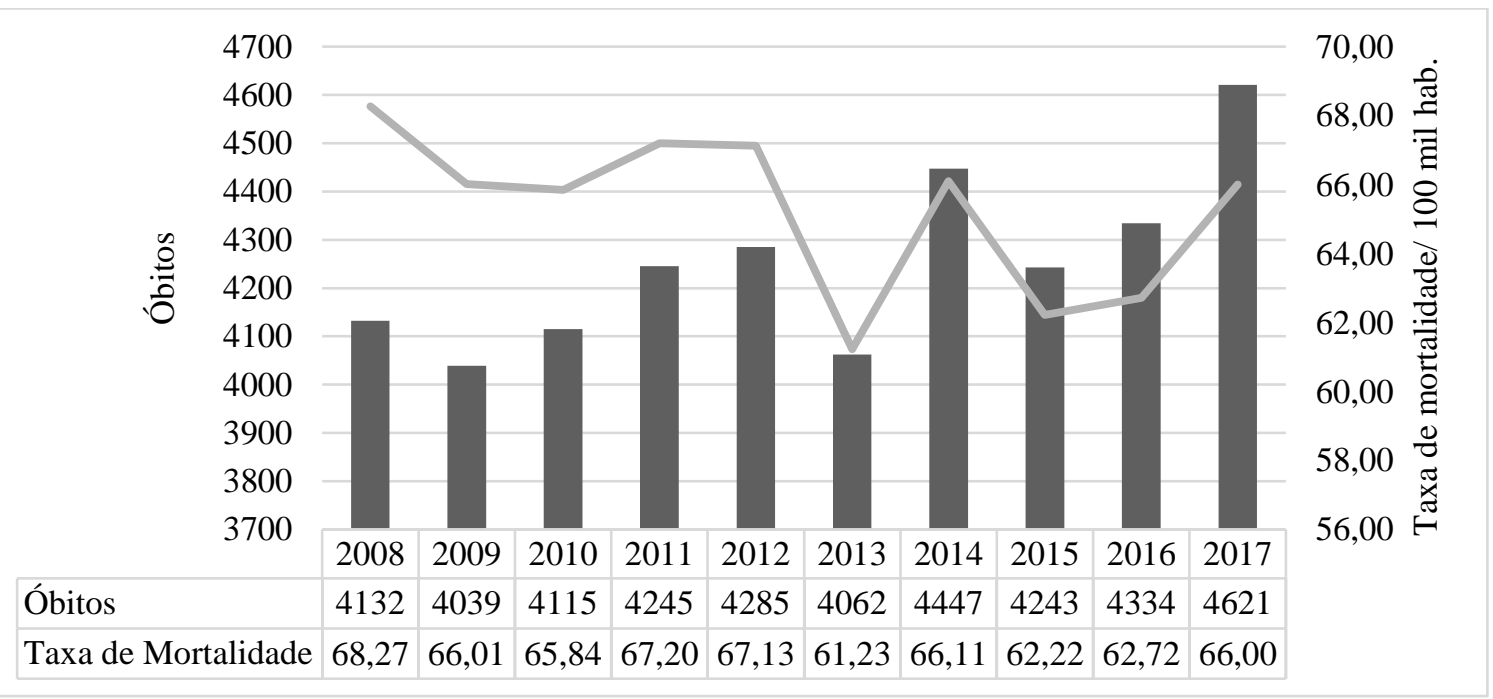

Fonte: Sistema De Informação Sobre Mortalidade, 2020 e Instituto Brasileiro De Geografia e Estatística, 2020.

$\mathrm{Na}$ análise detalhada das causas externas, os acidentes de transporte ocorreram em maior proporção (42\%), seguido de outras causas externas de lesões acidentais (20,7\%), agressões $(20,3 \%)$, lesões autoprovocadas voluntariamente $(13,7 \%)$, evento cuja intenção é indeterminada $(2,1 \%)$, complicações da assistência médica e cirúrgica $(0,5 \%)$, intervenções legais e operações de guerra $(0,4 \%)$ e sequelas de causas externas $(0,4 \%)$. 
Dentre os acidentes de transporte, os óbitos envolvem principalmente motociclistas (30,5\%), ocupantes de automóveis (30\%) e pedestres (15,6\%). Nas agressões, as mortes estão associadas ao uso de armas de fogo $(60,9 \%)$, enquanto nas lesões autoprovocadas, os óbitos ocorrem por enforcamento, estrangulamento ou sufocação $(73,2 \%)$. Nas outras causas externas de traumatismos acidentais, os óbitos ocorrem por quedas $(47,4 \%)$, afogamento e submersão acidentais (21,7\%). Nas complicações de assistência médica e cirúrgica, as mortes decorrem por reações anormais em pacientes ou complicações tardias causadas por procedimentos cirúrgicos e outros procedimentos médicos sem menção de acidente ao tempo do procedimento $(89,2 \%)$.

Em relação a distribuição geográfica dos óbitos, no estado de SC, quatro regiões de saúde, das dezesseis existentes, concentram as mortes (49,8\%): Foz do Rio Itajaí (10,8\%), Grande Florianópolis (15,7\%), Médio Vale do Itajaí $(10,2 \%)$ e Nordeste $(13,1 \%)$.

Dentre os quatro grupos que respondem pela quase totalidade dos óbitos por causas externas $(96,6 \%)-$ acidentes de transporte, outras causas externas de lesões acidentais, agressões e lesões autoprovocadas houve uma redução nas mortes por acidentes de transporte a partir do ano de 2014. Por outro lado, no mesmo período, ocorre aumento nas taxas de mortalidade para as demais causas - outras causas externas de lesões acidentais (14,2 em 2014 para 15,8 em 2017), lesões autoprovocadas (8,7 em 2014 para 10,6 em 2017) e agressões (12,8 em 2014 para 14,9 em 2017) (Tabela 1).

Tabela 1 - Número de óbitos e taxa de mortalidade (por 100 mil hab.) por grande grupo de causas externas (CID10). Santa Catarina, 2008 a 2017.

\begin{tabular}{|c|c|c|c|c|c|c|c|c|c|c|}
\hline Grande Grupo CID10 & 2008 & 2009 & 2010 & 2011 & 2012 & 2013 & 2014 & 2015 & 2016 & 2017 \\
\hline Acidentes de transporte & 1878 & 1870 & 1889 & 2025 & 1954 & 1721 & 1882 & 1593 & 1526 & 1522 \\
\hline Taxa de mortalidade & 31,0 & 30,6 & 30,2 & 32,1 & 30,6 & 25,9 & 28,0 & 23,4 & 22,1 & 21,7 \\
\hline $\begin{array}{l}\text { Out. causas exter. de lesões } \\
\text { acidentais }\end{array}$ & 775 & 691 & 754 & 784 & 870 & 877 & 955 & 971 & 1004 & 1105 \\
\hline Taxa de mortalidade & 12,8 & 11,3 & 12,1 & 12,4 & 13,6 & 13,2 & 14,2 & 14,2 & 14,5 & 15,8 \\
\hline Lesões autoprovoc. voluntariamente & 488 & 519 & 530 & 520 & 548 & 568 & 587 & 637 & 674 & 739 \\
\hline Taxa de mortalidade & 8,1 & 8,5 & 8,5 & 8,2 & 8,6 & 8,6 & 8,7 & 9,3 & 9,8 & 10,6 \\
\hline Agressões & 795 & 815 & 821 & 803 & 811 & 775 & 863 & 932 & 964 & 1040 \\
\hline Taxa de mortalidade & 13,1 & 13,3 & 13,1 & 12,7 & 12,7 & 11,7 & 12,8 & 13,7 & 13,9 & 14,9 \\
\hline $\begin{array}{l}\text { Eventos cuja intenção é } \\
\text { indeterminada }\end{array}$ & 156,0 & 115,0 & 96,0 & 89,0 & 56,0 & 64,0 & 80,0 & 48,0 & 81,0 & 122,0 \\
\hline Taxa de mortalidade & 2,6 & 1,9 & 1,5 & 1,4 & 0,9 & 1,0 & 1,2 & 0,7 & 1,2 & 1,7 \\
\hline Interv. legais e operações de guerra & 7,0 & 5,0 & 2,0 & 8,0 & 10,0 & 14,0 & 42,0 & 25,0 & 20,0 & 26,0 \\
\hline Taxa de mortalidade & 0,1 & 0,1 & 0,0 & 0,1 & 0,2 & 0,2 & 0,6 & 0,4 & 0,3 & 0,4 \\
\hline Compl. assistência médica e cirúrgica & 13,0 & 16,0 & 13,0 & 6,0 & 16,0 & 20,0 & 12,0 & 24,0 & 49,0 & 44,0 \\
\hline Taxa de mortalidade & 0,2 & 0,3 & 0,2 & 0,1 & 0,3 & 0,3 & 0,2 & 0,4 & 0,7 & 0,6 \\
\hline Sequelas de causas externas & 20,0 & 8,0 & 10,0 & 10,0 & 20,0 & 23,0 & 26,0 & 13,0 & 16,0 & 23,0 \\
\hline Taxa de mortalidade & 0,3 & 0,1 & 0,2 & 0,2 & 0,3 & 0,3 & 0,4 & 0,2 & 0,2 & 0,3 \\
\hline Total & 4132 & 4039 & 4115 & 4245 & 4285 & 4062 & 4447 & 4243 & 4334 & 4621 \\
\hline Taxa de mortalidade $\mathrm{g}$ & 68,3 & 66,0 & 65,9 & 67,2 & 67,1 & 61,2 & 66,1 & 62,2 & 62,7 & 66,0 \\
\hline
\end{tabular}

Fonte: Sistema De Informação Sobre Mortalidade, 2020; Instituto Brasileiro De Geografia e Estatística, 2020.

Quanto a escolaridade, o tempo de estudo das pessoas que vieram à óbito é de 04 a 07 anos $(29,7 \%)$, seguido de 08 a 11 anos (25,7\%), 01 a 03 anos (15,4\%), 12 anos ou mais $(6,6 \%)$ e nenhuma escolaridade (2,9\%). Este dado foi ignorado em $19,7 \%$ das ocorrências. Os óbitos ocorreram principalmente em pessoas do sexo masculino $(79,6 \%)$. A assistência médica e cirúrgica foi a única exceção entre os grupos de causas, em que os óbitos no sexo feminino (54\%) superam os masculinos (46\%). A análise da faixa etária demonstra que mais da metade dos óbitos ocorrem entre 20 aos 49 anos de idade $(56,4 \%)$ (Tabela 2 ). 
Tabela 2 - Número de óbitos e proporção por grande grupo de causas externas (CID10) e faixa etária. Santa Catarina, 2008 a 2017.

\begin{tabular}{|c|c|c|c|c|c|c|c|c|c|c|c|c|c|c|c|}
\hline Grupos de causas $^{1}$ & & $\begin{array}{l}\text { O } \\
\frac{C}{\sigma} \\
\bar{v}\end{array}$ & $\begin{array}{l}\text { ர } \\
\text { ర }\end{array}$ & $\begin{array}{l}0 \\
\pi \\
0\end{array}$ & $\begin{array}{l}+ \\
\sigma \\
0 \\
\square\end{array}$ & $\begin{array}{l}\sigma \\
\sigma \\
0 \\
\sigma\end{array}$ & $\begin{array}{l}\text { I } \\
\text { ర } \\
\text { 이 }\end{array}$ & $\begin{array}{l}\text { 尺 } \\
\text { ర } \\
\text { 요 }\end{array}$ & $\begin{array}{l}\text { g } \\
\text { ல } \\
\text { ㅇ } \\
\end{array}$ & $\begin{array}{l}\text { 오 } \\
\text { (ర) } \\
\text { 유 } \\
\end{array}$ & $\begin{array}{l}\text { ஜ } \\
\text { ర } \\
8 \\
\end{array}$ & $\begin{array}{l}R \\
0 \\
R\end{array}$ & $\hat{\varnothing}$ & $\lg n$ & Total \\
\hline \multirow{2}{*}{ V01-V99 } & $\mathrm{N}$ & 62 & 161 & 240 & 267 & 1636 & 4690 & 3364 & 2853 & 2132 & 1353 & 758 & 320 & 24 & 17860 \\
\hline & $\%$ & 0,3 & 0,9 & 1,3 & 1,5 & 9,2 & 26,3 & 18,8 & 16 & 11,9 & 7,6 & 4,2 & 1,8 & 0,1 & 100 \\
\hline \multirow{2}{*}{ W00-X59 } & $\mathrm{N}$ & 144 & 193 & 120 & 215 & 420 & 942 & 958 & 1146 & 1072 & 840 & 913 & 1806 & 17 & 8786 \\
\hline & $\%$ & 1,6 & 2,2 & 1,4 & 2,4 & 4,8 & 10,7 & 10,9 & 13 & 12,2 & 9,6 & 10,4 & 20,6 & 0,2 & 100 \\
\hline \multirow{2}{*}{ X60-X84 } & $\mathrm{N}$ & - & - & 1 & 54 & 270 & 984 & 1019 & 1187 & 1135 & 666 & 348 & 146 & - & 5810 \\
\hline & $\%$ & - & - & 0 & 0,9 & 4,6 & 16,9 & 17,5 & 20,4 & 19,5 & 11,5 & 6 & 2,5 & - & 100 \\
\hline \multirow{2}{*}{ X85-Y09 } & $\mathrm{N}$ & 15 & 15 & 18 & 89 & 1181 & 2931 & 2014 & 1236 & 647 & 293 & 115 & 44 & 21 & 8619 \\
\hline & $\%$ & 0,2 & 0,2 & 0,2 & 1 & 13,7 & 34 & 23,4 & 14,3 & 7,5 & 3,4 & 1,3 & 0,5 & 0,2 & 100 \\
\hline \multirow{2}{*}{ Y10-Y34 } & $\mathrm{N}$ & 4 & 11 & 5 & 20 & 35 & 135 & 162 & 150 & 115 & 74 & 68 & 123 & 5 & 907 \\
\hline & $\%$ & 0,4 & 1,2 & 0,6 & 2,2 & 3,9 & 14,9 & 17,9 & 16,5 & 12,7 & 8,2 & 7,5 & 13,6 & 0,6 & 100 \\
\hline \multirow{2}{*}{ Y35-Y36 } & $\mathrm{N}$ & - & - & - & 2 & 33 & 81 & 27 & 12 & 3 & - & 1 & - & - & 159 \\
\hline & $\%$ & - & - & - & 1,3 & 20,8 & 50,9 & 17 & 7,5 & 1,9 & - & 0,6 & - & - & 100 \\
\hline \multirow{2}{*}{ Y40-Y84 } & $\mathrm{N}$ & 1 & - & 1 & - & 6 & 11 & 13 & 13 & 23 & 52 & 57 & 36 & - & 213 \\
\hline & $\%$ & 0,5 & - & 0,5 & - & 2,8 & 5,2 & 6,1 & 6,1 & 10,8 & 24,4 & 26,8 & 16,9 & - & 100 \\
\hline \multirow{2}{*}{ Y85-Y89 } & $\mathrm{N}$ & - & 1 & 2 & 1 & 4 & 13 & 19 & 28 & 27 & 19 & 14 & 41 & - & 169 \\
\hline & $\%$ & - & 0,6 & 1,2 & 0,6 & 2,4 & 7,7 & 11,2 & 16,6 & 16 & 11,2 & 8,3 & 24,3 & - & 100 \\
\hline \multirow{2}{*}{ Total } & $\mathrm{N}$ & 226 & 381 & 387 & 648 & 3585 & 9787 & 7576 & 6625 & 5154 & 3297 & 2274 & 2516 & 67 & 42523 \\
\hline & $\%$ & 0,5 & 0,9 & 0,9 & 1,5 & 8,4 & 23 & 17,8 & 15,6 & 12,1 & 7,8 & 5,3 & 5,9 & 0,2 & 100 \\
\hline
\end{tabular}

Legenda: ${ }^{1}$ Acidentes de transporte (V01-V99), outras causas externas de traumatismos acidentais (W00-X59), lesões autoprovocadas intencionalmente (X60$\mathrm{X} 84)$, agressões (X85-Y09), eventos cuja intenção é indeterminada (Y10-Y34), intervenções legais e operações de guerra (Y35-Y36), complicações de assistência médica e cirúrgica (Y40-Y84), sequelas de causas externas de morbidade e de mortalidade (Y85-Y89).

Fonte: Sistema de Informação sobre Mortalidade, 2020. 
Quando a característica cor foi levada em consideração, os óbitos ocorreram em ordem decrescente em pessoas consideradas brancas $(87,3 \%)$, pardas $(7,9 \%)$, pretas $(2,8 \%)$, indígenas $(0,2 \%)$ e amarelas $(0,1 \%)$. A taxa de mortalidade acumulada do período mostra que ocorreram 707,6 óbitos por 100 mil hab. em brancos, 636,9/100 mil hab. em pretos, 455,1/100 mil hab. em indígenas, 435,2/100 mil hab. em pardos e 130,7/100 mil hab. em amarelos. A proporção de homens que morrem em comparação às mulheres na população preta $(86,7 \%)$ e parda $(85,4 \%)$ foi maior em comparação à branca $(78,9 \%)$, amarela $(79,4 \%)$ e indígena $(79,5 \%)$.

Houve alternâncias quando analisadas as variáveis idade e cor. A proporção de óbitos por causas externas que ocorreram na faixa etária dos 20 aos 49 anos variou conforme a cor das pessoas: pretas $(70,5 \%)$, pardas $(66,8 \%)$, brancas $(55 \%)$, indígenas $(50,7 \%)$ e amarelas $(41,2 \%)$. Uma diferença também foi visualizada na relação entre causa de mortalidade e cor das pessoas. Enquanto os brancos morrem mais em consequência de acidentes de trânsito (43\%), os óbitos por agressões atingem mais pretos (37,1\%), pardos $(35,1 \%)$ e indígenas (34,2\%) (Gráfico 2).

Gráfico 2 - Proporção de óbitos por grande grupo de causas externas (CID10) e raça. Santa Catarina, 2008 a 2017.

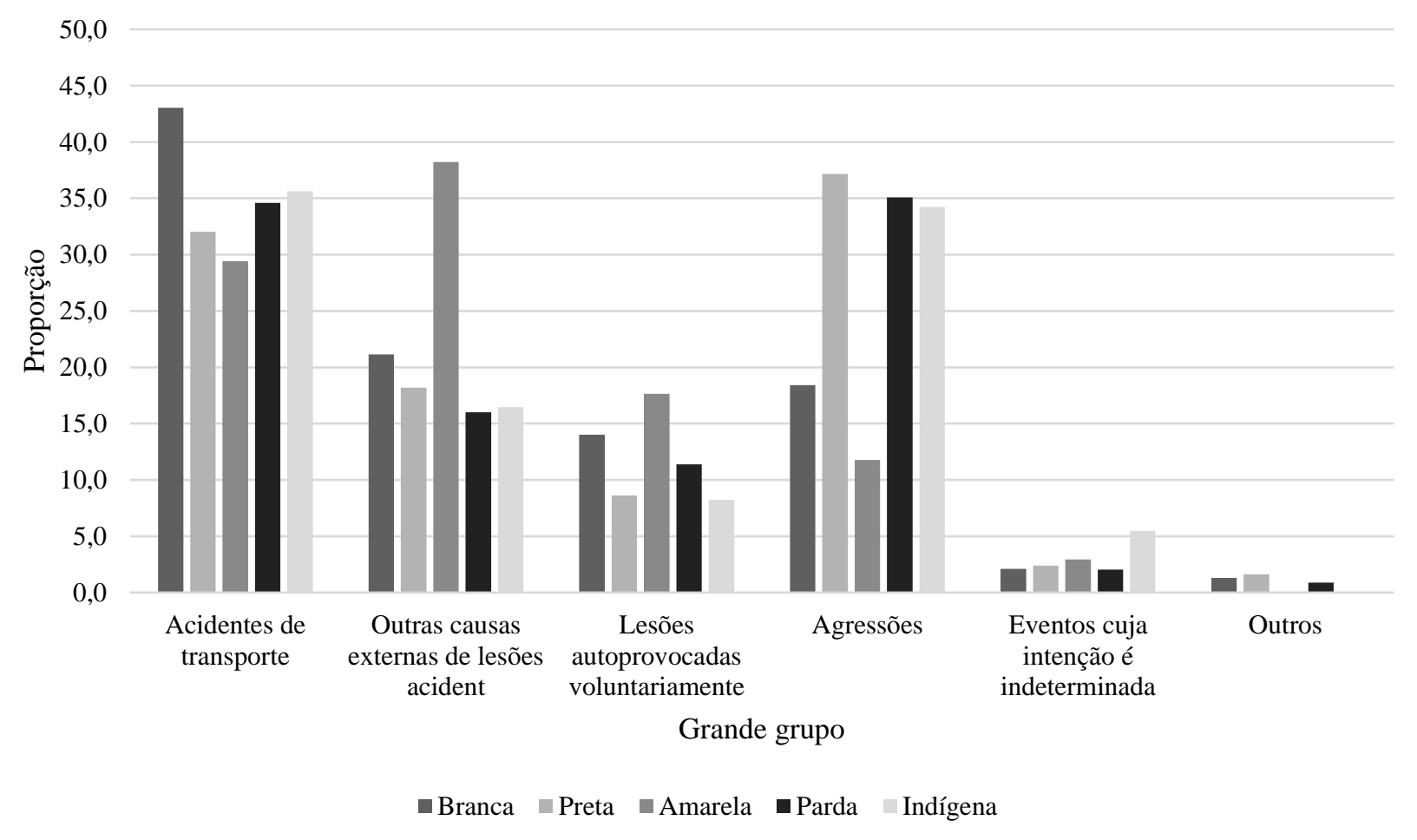

Fonte: Sistema de Informação sobre Mortalidade, 2020

\section{DISCUSSÃO}

A análise por faixa etária, sexo e raça evidenciou que alguns grupos são mais afetados em SC, expressando as determinações sociais na ocorrência dessas situações. A população de SC, conforme censo de 2010 , é composta por brancos $(84 \%)$, na maioria, seguida de pardos $(12,4 \%)$, pretos $(2,9 \%)$, amarelos $(0,4 \%)$ e indígenas $(0,3 \%)$ (INSTITUTO BRASILEIRO DE GEOGRAFIA E ESTATÍSTICA, 2010). Dessa forma, poderia esperar-se que proporcionalmente a população de cor branca fosse a mais afetada. Entretanto, as taxas de mortalidade evidenciam que referente a violência, os grupos sociais não brancos são mais afetados.

A violência expressa, assim como outras dimensões da vida social, as diferenças de cor da população. Além disto, as mortes por causas externas atingem uma população jovem, aspecto que traz consequências demográficas e econômicas (JORGE MHPM e LATORRE MRDO, 1994; CARVALHO AX, et al., 2007). Os óbitos podem ser considerados evitáveis, já que decorrem de causas eminentemente sociais e historicamente 
situadas. Além disso, os custos financeiros decorrentes da assistência médica envolvendo as vítimas são significativos, já que para cada vítima fatal, existem 17 não fatais (INSTITUTO DE PESQUISA ECONÔMICA APLICADA, 2003; SOUZA ER e LIMA MLC, 2006).

No período de 1980 a 2005, os homicídios e os acidentes de trânsito foram responsáveis por $15 \%$ do total de óbitos no país, embora com diferenças entre os municípios brasileiros (MINAYO MCS, 2009). No ano 2000, os homicídios envolvendo armas de fogo foram a principal causa, seguido pelos acidentes de transporte, com uma taxa de mortalidade de 69,7 para cada 100 mil hab. (GAWRYSZEWSKI VP, et al., 2004). Em 2003 os acidentes e as violências foram responsáveis por $12,6 \%$ dos óbitos no Brasil, representando uma taxa de mortalidade de 71,6 óbitos por 100 mil hab., semelhante ao que ocorreu no ano seguinte (SOUZA ER e LIMA MLC, 2006; FILHO MM e JORGE MHPM, et al., 2007). Em 2015, a taxa foi de 81,2/100 mil hab., assim, as taxas do país como um todo são superiores ao que se encontra em SC (LADEIRA RM, et al., 2017).

Apesar disso, os estados da região sul têm apresentado um aumento na mortalidade por causas externas nos últimos anos, o que permite relativizar a narrativa hegemônica dos elevados índices de desenvolvimento econômico da região. O Paraná apresentou uma tendência de aumento nas taxas de mortalidade por violência interpessoal entre 2000 e 2015. No Rio Grande do Sul, no mesmo período, na violência interpessoal apresentou um aumento de $12 \%$ na taxa de mortalidade. Em 2015, a violência interpessoal e os acidentes de trânsito estavam entre os dez agravos com maior taxa de mortalidade. (MINISTÉRIO DA SAÚDE, 2018).

Um estudo que avaliou os homicídios entre homens de 10 a 24 anos em $74 \%$ dos municípios do Paraná e $61 \%$ de Santa Catarina, mostrou uma taxa de mortalidade maior nos municípios paranaenses, especialmente aqueles localizados na fronteira com o Paraguai. Ainda, levando em consideração os indicadores de desigualdade social e socioeconômicos, as taxas mais elevadas ocorreram em cidades com maior porte e crescimento populacional, urbanizadas, com número maior de moradores por domicílio e maior desigualdade de renda (MANSANO NH, et al., 2013), situação que se reflete em SC.

O perfil dos óbitos por causas externas já identificado nos anos 1980, que ocorre, principalmente, com homens, na faixa etária dos 20 aos 39 anos, ainda se mantém no período analisado, com risco de morrer cada vez mais alto quando comparado às mulheres (MINAYO MCS e SOUZA ER, 1993; WAISELFISZ JJ, 2015; SOUSA ASB, et al., 2016). Apesar de afetar principalmente o sexo masculino, os óbitos em decorrência de arma de fogo, também tem aumentando entre as mulheres (MINAYO MCS, 2009). Estudo realizado em São Paulo, demonstrou que $14,1 \%$ dos homicídios ocorreram atingindo o sexo feminino, sendo que a principal causa era o feminicídio (CAICEDO-ROA M, et al, 2019).

Em 2010, a mortalidade foi de 178 óbitos a cada 100 mil hab. para os homens e 24/100 mil hab. para as mulheres (MOURA EC, et al., 2015). Os homens possuem um risco maior de morrer comparado às mulheres, aumentando entre 4 e 5 vezes, quando se analisa os acidentes de transporte (D'AGOSTINI RA, 2005; JORGE MHPM, et al., 2007; GAWRYSZEWSKI VP, et al., 2004; LADEIRA RM, et al., 2017). Além disso, maior exposição de risco e consumo de álcool e drogas ilícitas, decorrente de diferentes padrões de comportamento social construídos sobre o sexo, podem estar associados aos homicídios nos homens (BARATA RB, 2009).

A mortalidade por causas externas no núcleo metropolitano de Florianópolis/SC, que envolve nove municípios catarinenses, no período de 1996 a 2002, representa a terceira causa de óbito. As principais causas foram os acidentes de trânsito, seguido pelos homicídios, suicídios e outras causas. A taxa de mortalidade foi de 68,3 para cada 100 mil habitantes e, a cor de pele mais frequente na certidão de óbito foi a branca $(51,5 \%)$, dado inferior ao encontrado na presente análise. Neste mesmo estudo, também era registrado um decréscimo na taxa de mortes por acidentes, ao mesmo tempo em que crescia o número de mortes por homicídios (D'AGOSTINI RA, 2005).

Avaliando a mortalidade em Tubarão/SC, no ano de 2009, 20\% dos óbitos registrados estavam associados a causas externas, envolvendo principalmente os acidentes de trânsito. As vítimas tinham média de 37 anos de idade, do sexo masculino e com baixa escolaridade. Entre os prováveis motivos para o elevado número de óbitos por acidentes de trânsito, está o fato da BR-101, um dos principais eixos rodoviários do país, atravessar a cidade (TREVISOL FS, et al., 2009). 
Os dados por região de saúde em SC indicam um maior número de óbitos por acidentes de trânsito no Médio Vale do Itajaí, região que tem como via rodoviária principal a BR-470, que permite o acesso ao litoral do estado. As condições dessa rodovia podem servir como um fator de risco para a mortalidade associada aos acidentes de trânsito na região. Buscando explicar os acidentes de transporte, com base em dados de dois inquéritos nacionais, a associação entre consumo de bebidas e direção de veículos foi maior nos motoristas do sexo masculino e com idade entre 18 e 29 anos (MALTA DC, et al., 2015).

O Código Brasileiro de Trânsito (CTB) foi implantado em 1997, através da Lei 9.503 publicada em setembro, no Diário Oficial da União. Essa lei passou por modificações posteriores, sendo que uma das principais alterações ocorreu com a Lei 11.705 de junho de 2008, que definiu o consumo zero de álcool. Essa lei também ficou conhecida como Lei Seca. Nela foi definido que o ato de dirigir sob o efeito de álcool ou qualquer outra substância psicoativa seria considerada infração gravíssima (BRASIL, 2008).

Em dezembro de 2012, através da Lei 12.760, houve modificações em dispositivos da Lei Seca, definindo aumento no valor da multa, de cinco para dez vezes e suspensão do direito de dirigir por 12 meses. Em caso de reincidência nesse período, a multa seria aplicada de forma dobrada. Além disso, como medida administrativa deveria ocorrer o recolhimento da habilitação e retenção do veículo em caso de abordagem (BRASIL, 2012). Em 2016, houve um enrijecimento da legislação, com a Lei 13.281. Ocorreu a inclusão de um artigo que estabeleceu que a recusa da submissão a teste ou exame clínico para conhecimento do uso de álcool ou de outra substância psicoativa já seria configurada como infração, gerando penalidade e multa (BRASIL, 2016).

Nesse sentido, algumas análises têm associado o impacto dessa legislação na mortalidade por acidentes de transporte. O Instituto de Pesquisa Econômica Aplicada (2016), em estudo das mortes por acidentes de trânsito no período de 1996 a 2013, indicou que a implementação ou alteração na legislação de trânsito reflete na diminuição no número dos óbitos em curto espaço de tempo, embora no longo prazo essa tendência é modificada. Reduções foram identificadas posteriormente a implantação do CBT e a Lei Seca. Estudo semelhante foi realizado no Paraná, verificando que ocorreu redução nas taxas de mortalidade nesses dois momentos, embora sem manutenção ao longo do tempo (ABREU DROM et al., 2018).

Assim, é necessário que as medidas de educação e fiscalização sejam constantes a fim de evitar uma acomodação das pessoas quanto as ações a serem adotadas de segurança no trânsito (INSTITUTO DE PESQUISA ECONÔMICA APLICADA, 2016; ABREU DROM et al., 2018). Apesar da análise em SC ser do período de dez anos, percebemos uma redução do número de acidentes de transporte nos anos posteriores às mudanças na legislação de trânsito, situação que se manteve nos últimos anos. Esse fato pode estar associado à fiscalização realizada e mantida pelo poder público, embora é necessário uma análise mais aprofundada para mensurar os impactos dessas medidas na redução dos acidentes.

Apesar da redução das taxas de mortalidade por acidentes de transporte, vemos por outro lado, uma elevação nas taxas envolvendo agressões. No Brasil, entre 1980 e 2014, morreram aproximadamente um milhão de pessoas em decorrência de algum tipo de lesão provocada por arma de fogo, destacando-se os homicídios. Em comparação ao primeiro e último ano do período, houve um crescimento de mais de $400 \%$ no número de óbitos. Diferente dos homicídios, que se concentram em determinados espaços sociais, os acidentes de transporte ocorrem de forma cada vez mais dispersa (WAISELFISZ JJ, 2015; MINAYO MCS, 2009).

A frustração das expectativas, o desemprego e ausência de participação na vida social de parcelas da população que vivem em situações de exclusão social contribui para o aparecimento de comportamentos violentos (BARATA RB, 2009).

Assim como em SC, observa-se diferença quando se analisa a mortalidade por causas externas a partir do critério cor das pessoas. Em 2003, as taxas de homicídios observadas na população negra foram maiores em todas as faixas etárias quando comparadas à branca. Dessa forma, a desigualdade entre diferentes grupos contribui, também, para a ocorrência diferenciada das mortes violentas, com maior incidência dessas nos segmentos mais pobres e pretos/pardos (SOUZA ER e LIMA MLC, 2006). 
O perfil das vítimas de homicídios por armas de fogo mostra que morrem 2,6 vezes mais pretos quando comparado aos brancos entre 2003 e 2014 (WAISELFISZ JJ, 2015). Em 2016, 71,5\% dos indivíduos assassinados no Brasil foram pretos ou pardos (CERQUEIRA D, et al., 2018). A morte violenta, mesmo em um estado em que a população branca é majoritária, incide mais significativamente nas populações pretas e pardas, conforme as taxas de mortalidade. Essa situação é um indicativo da desigualdade e exclusão social a que segmentos da população estão sujeitas e que tem como uma das consequências a maior violência e morte de população preta e jovem (WAISELFISZ JJ, 2015; CERQUEIRA D, et al., 2018).

As crianças e idosos também têm se sobressaído nos estudos, tendo as taxas de mortalidade crescido entre estas gerações (GAWRYSZEWSKI VP, et al., 2004; SOUZA ER e LIMA MLC, 2006; MINAYO MCS, 2009; NERY AA, et al., 2013). Em SC, isso pode ser percebido nas outras causas externas de lesões acidentais, em que as quedas são frequentes, e as pessoas com mais de 60 anos são as mais afetadas. Com isso, os dados mostram a complexidade da violência, sendo necessário compreender as especificidades locais para programar e implementar ações multisetoriais (MINAYO MCS, 2009; MOURA EC, et al., 2015).

\section{CONCLUSÃO}

Esta pesquisa trouxe elementos para analisar o perfil dos óbitos por causas externas em SC. No período avaliado, evidenciou-se que o principal motivo das mortes foram os acidentes de transporte, a população mais atingida foi a de sexo masculino, entre 20 e 49 anos de idade e de cor branca. As taxas de mortalidade por acidentes de trânsito apresentam uma redução nos últimos anos enquanto essa tendência é inversa para as agressões. A proporção de homicídios em homens jovens, de cor preta e parda, é significativa, expressando a dimensão social e histórica da violência e das desigualdades que atinge essa população. São necessários, evidentemente, estudos que aprofundem a análise destes dados, bem como ações políticas que mitiguem a dura realidade social que estas mortes evitáveis expressam.

\section{REFERÊNCIAS}

1. ABREU DROM, et al. Impacto do Código de Trânsito Brasileiro e da Lei Seca na mortalidade por acidentes de trânsito. Cadernos de Saúde Pública, 2018; 34(8): 1-13.

2. BARATA RB. Relações de gênero e saúde: desigualdade ou discriminação? In: BARATA, R. B. Como e Por Que as Desigualdades Sociais Fazem Mal à Saúde. Rio de Janeiro: Editora Fiocruz, 2009; $241 \mathrm{p}$.

3. BRASIL. Lei 11.705, de 19 de junho de 2008. Altera a Lei no 9.503, de 23 de setembro de 1997, que "institui o Código de Trânsito Brasileiro", e a Lei no 9.294, de 15 de julho de 1996, que dispõe sobre as restrições ao uso e à propaganda de produtos fumígeros, bebidas alcoólicas, medicamentos, terapias e defensivos agrícolas, nos termos do $\S 40$ do art. 220 da Constituição Federal, para inibir o consumo de bebida alcoólica por condutor de veículo automotor, e dá outras providências. Diário Oficial da União, 20 jun. 2008.

4. BRASIL. Lei 12.760 de 20 de dezembro de 2012. Altera a Lei No 9.503, de 23 de setembro de 1997, que institui o Código de Trânsito Brasileiro. Diário Oficial da União, 21 dez. 201.

5. BRASIL. Lei 13.281 de 04 de maio de 2016. Altera a Lei No 9.503, de 23 de setembro de 1997 (Código de Trânsito Brasileiro), e a Lei No 13.146, de 6 de julho de 2015. Diária Oficial da União, 05 maio 2016.

6. CAICEDO-ROA M, et al. Feminicídios na cidade de Campinas, São Paulo, Brasil. Cadernos de Saúde Pública, 2019; 35(6): 1-11.

7. CARVALHO AX, et al. Textos para discussão no 1268 - Custos das mortes por causas externas no Brasil. Brasília: IPEA, 2007; 45p.

8. CERQUEIRA D, et al. Atlas da Violência 2018. Rio de Janeiro: IPEA, Fórum Brasileiro de Segurança Pública, 2018; 93p.

9. COSTA MFL, BARRETO SM. Tipos de estudos epidemiológicos: conceitos básicos e aplicações na área do envelhecimento. Epidemiologia e Serviços de Saúde, 2003; 12(4): 189-201.

10. D'AGOSTINI RA. Violência e morte na região metropolitana de Florianópolis, Brasil: tendências da mortalidade por causas externas de 1996 a 2002. Dissertação (Mestrado em Saúde Pública) - Universidade Federal de Santa Catarina, Florianópolis, 2005; 140p.

11. FILHO MM, JORGE MHPM. Características da morbidade por causas externas em serviço de urgência. Revista Brasileira de Epidemiologia, 2007; 10(4): 579-591. 
12. GAWRYSZEWSKI VP, et al. As causas externas no Brasil no ano 2000: comparando a mortalidade e a morbidade. Cadernos de Saúde Pública, 2004; 20: 995-1003.

13. INSTITUTO BRASILEIRO DE GEOGRAFIA E ESTATíSTICA. Pessoas de 5 anos ou mais de idade, total e as alfabetizadas, por cor ou raça, segundo a situação do domicílio e a idade. 2010. Disponível em: https://sidra.ibge.gov.br/tabela/1379\#resultado. Acesso em: 08 jan. 2020.

14. INSTITUTO DE PESQUISA ECONÔMICA APLICADA. Impactos sociais e econômicos dos acidentes de trânsito nas aglomerações urbanas: sínteses da pesquisa. Brasília, 2003.

15. INSTITUTO DE PESQUISA ECONÔMICA APLICADA. Mortes por acidentes de transporte terrestre no Brasil: análise dos sistemas de informação do Ministério da Saúde. Rio de Janeiro: Ipea, 2016; 50p.

16. JORGE MHP, et al. Causas externas: o que são, como afetam o setor saúde, sua medida e alguns subsídios para a sua prevenção. Revista Saúde, 2007; 1: 37-47.

17. JORGE MHPM, LATORRE MRDO. Acidentes de trânsito no Brasil: dados e tendências. Cadernos de Saúde Pública, 1994; 10(1): 19-44.

18. JORGE MPHM, et al. O sistema de informações sobre mortalidade: problemas e propostas para o seu enfrentamento I - Mortes por causas naturais. Epidemiologia e Serviços de Saúde, 2002; 5: 197-211.

19. LADEIRA RM, et al. Acidentes de transporte terrestre: estudo Carga Global de Doenças, Brasil e unidades federadas, 1990 e 2015. Revista Brasileira de Epidemiologia, 2017; 20: 157-170.

20. MALTA DC, et al. Consumo de bebidas alcoólicas e direção de veículos nas capitais brasileiras e no Distrito Federal, segundo dois inquéritos nacionais de saúde. Revista Brasileira de Epidemiologia, 2015; 18: 214-223.

21. MANSANO NH, et al. Homicídios em homens jovens de 10 a 24 anos e condições sociais em municípios do Paraná e Santa Catarina, Brasil, 2001 - 2010. Epidemiologia e Serviços de Saúde, 2013; 22: 203-214.

22. MICHAUD Y. A violência. São Paulo: Editora Ática, 1989.

23. MINAYO MCS. Seis características das mortes violentas no Brasil. Revista Brasileira de Estudos Populacionais, 2009; 26(1): 135-140.

24. MINAYO MCS, SOUZA ER. Violência para todos. Cadernos de Saúde Pública, 1993; 9(1): 65-78.

25. MINAYO MCS, SOUZA ER. É possível prevenir a violência? Reflexões a partir do campo da saúde pública. Ciência e Saúde Coletiva, 1999; 4(1): 7-23.

26. MINAYO MCS, SOUZA ER. Violência e saúde como um campo interdisciplinar e de ação coletiva. História, Ciência, Saúde-Manguinhos, 1998; 4(3): 513-531.

27. MINISTÉRIO DA SAÚDE. Saúde Brasil Estados 2018: uma análise de situação de saúde segundo o perfil de mortalidade dos estados brasileiros e do Distrito Federal. Brasília: Ministério da Saúde, 2018; 378p.

28. MOURA EC, et al. Desigualdade de gênero na mortalidade por causas externas no Brasil, 2010. Ciência e Saúde Coletiva, 2015; 20: 779-788.

29. NERY AA, et al. Perfil epidemiológico da morbimortalidade por causas externas em um hospital geral. Revista de Enfermagem UFPE Online, 2013; 7: 562-571.

30. ORGANIZAÇÃO MUNDIAL DA SAÚDE. Classificação estatística internacional de doenças e problemas relacionados à Saúde. 10. ed. São Paulo: Editora da Universidade de São Paulo, 2012.

31. PINTO LF, et al. Sistemas Nacionais de Informação e levantamentos populacionais: algumas contribuições do Ministério da Saúde e do IBGE para a análise das capitais brasileiras nos últimos 30 anos. Ciência e Saúde Coletiva, 2018; 23: 1859-1870.

32. SISTEMA DE INFORMAÇÃO SOBRE MORTALIDADE. Departamento de Informática do Sistema Único de Saúde. Óbitos por causas dernas. Disponível http://www2.datasus.gov.br/DATASUS/index.php?area=0205\&id=6940\&VObj=http://tabnet.datasus.gov.br/cgi/deftoh tm.exe?sim/cnv/ext10. Acesso em: 02. mar. 2020.

33. SOUSA ASB, et al. Mortalidade por causas externas em adultos jovens em Teresina-PI no período de 2001-2011. Revista Interdisciplinar, 2016; 9: 57-65.

34. SOUZA ER, LIMA MLC. Panorama da violência urbana no Brasil e suas capitais. Ciência e Saúde Coletiva, 2006; 1(supl.) 1211-1222.

35. TREVISOL FS, et al. Avaliação das mortes por causas externas na cidade de Tubarão (SC) no ano de 2009. Revista AMRIGS, 2011; 55: 25-30.

36. WAISELFISZ JJ. Mapa da violência 2016: homicídios por armas de fogo no Brasil. Brasília: FLACSO Brasil, 2015; $71 p$. 